\title{
Surface Dissolution and Diffusion of Oxygen Molecules in $\mathrm{SiO}_{2}$ Glass
}

\author{
Koichi KAJIHARA, ${ }^{*}$ Taisuke MIURA, ${ }^{*}, * *$ Hayato KAMIOKA, ${ }^{*}$ Masahiro HIRANO,* \\ Linards SKUJA ${ }^{*, * * *}$ and Hideo HOSONO ${ }^{*, * * * *}$ \\ ${ }^{*}{ }^{\dagger}$ Transparent Electro-Active Materials Project, ERATO, Japan Science and Technology Agency, \\ KSP C-1232, 3-2-1, Sakado, Takatsu-ku, Kawasaki-shi 213-0012 \\ **Solid-State Optical Science Research Unit, RIKEN, 2-1, Hirosawa, Wako-shi 351-0198 \\ ***Institute of Solid State Physics, University of Latvia, Kengaraga iela 8, LV1063 Riga, Latvia \\ ****Materials and Structures Laboratory, Tokyo Institute of Technology, 4259, Nagatsuta, Midori-ku, Yokohama-shi $226-8503$
}

\author{
$\mathrm{SiO}_{2}$ ガラスにおける酸素分子の表面溶解と拡散 \\ 梶原浩一* . 三浦泰祐 $*$,** . 上岡隼人*. 平野正浩* . Linards Skuja*,*** . 細野秀雄*,**** \\ *,†科学技術振興機構 ERATO 透明電子活性プロジェクト，213-0012 川崎市高津区坂戸 3-2-1 KSP C-1232 \\ **理化学研究所固体光学デバイス研究ユニット, 351-0198 和光市広沢 2-1 \\ ***ラトビア大学固体物理学研究所, Kengaraga iela 8, LV1063 Riga, Latvia \\ ****東京工業大学応用セラミックス研究所, 226-8503 横浜市緑区長津田 4259
}

\begin{abstract}
Surface dissolution and diffusion of oxygen molecules $\left(\mathrm{O}_{2}\right)$ in $\mathrm{SiO}_{2}$ glass were studied by their photoluminescence at $1272 \mathrm{~nm}$ excited with a titanium sapphire laser oscillating at $765 \mathrm{~nm}$. The dissolution of $\mathrm{O}_{2}$ from ambient atmosphere at both surfaces was much faster than the following diffusion of $\mathrm{O}_{2}$ into $\mathrm{SiO}_{2}$ glass, indicating that the surface dissolution is not the rate-limiting step for the saturation of $\mathrm{SiO}_{2}$ glass with $\mathrm{O}_{2}$. The time- and temperature-dependent concentration changes of $\mathrm{O}_{2}$ allow to evaluate the diffusion coefficient and the saturation solubility of $\mathrm{O}_{2}$ in $\mathrm{SiO}_{2}$ glass.

[Received June 7, 2004; Accepted July 30, 2004]
\end{abstract}

Key-words : $\mathrm{SiO}_{2}$ glass, Interstitial oxygen molecule, Surface dissolution, Diffusion, Photoluminescence

1. Introduction

Diffusion of oxygen in oxides is closely related to various important phenomena in oxides such as oxidation and corrosion of metals, sintering, and transport of oxide ions in oxide electrolytes, and radiation-induced defect processes. ${ }^{1), 2)}$ Several techniques have been developed to study the diffusion of oxygen in oxides. A straightforward way is the permeation method which measures amount of oxygen passed through thin plate or film samples. ${ }^{3)}$ Isotopic labeling is very useful to trace the rearrangement of oxygen induced by the diffusion. ${ }^{4-12)}$ Mobility of charged oxygen can be evaluated by electrochemical methods because the Nernst-Einstein equation relates the diffusion coefficient and the ionic conductivity. However, it is not generally easy to characterize separately transports of oxygens of different chemical forms and via different diffusion paths such as lattice interstitials, vacancies, and grain boundaries.

The oxygen molecule $\left(\mathrm{O}_{2}\right)$ is particularly interesting among possible mobile oxygen species since it is selectively probed by its infrared photoluminescence (PL) band at $1272 \mathrm{~nm}$, attributed to the transition from the first singlet excited state $\left(a^{1}\right.$ $\left.\Delta_{\mathrm{g}}\right)$ to the triplet ground state $\left(X^{3} \Sigma_{\mathrm{g}}^{-}\right)$. It was noted that this $\mathrm{PL}$ band is detectable even for a very low concentration of $\mathrm{O}_{2}$ in $\mathrm{SiO}_{2}$ glass $\left(\sim 10^{14} \mathrm{~cm}^{-3}\right)$ by populating the second singlet excited state of $\mathrm{O}_{2}\left(b^{1} \Sigma_{\mathrm{g}}{ }^{+}\right)$at $765 \mathrm{~nm}$ with titanium sapphire laser light. ${ }^{13)}$ These properties are quite useful to investigate the diffusion of $\mathrm{O}_{2}$ in $\mathrm{SiO}_{2}$ glass. ${ }^{14)}$

Surface dissolution of $\mathrm{O}_{2}$ into oxides has been little studied. Direct uptake of $\mathrm{O}_{2}$ from ambient atmosphere may be

\footnotetext{
${ }^{\dagger}$ Present address : SORST, JST, 4259, Nagatsuta, Midori-ku, Yokohama-shi 226-8503 現在: 科学技術振興機構 SORST, 226-8503 横浜市緑区長津田 4259
}

relatively fast because the chemical state of oxygen is largely preserved. In contrast, surface dissolution of oxygen into oxides sometimes involves activation processes which slow down the dissolution rate. For example, dissolution of oxygen in solid oxide electrolytes is considerably slow, because $\mathrm{O}_{2}$ has to be converted into a pair of $\mathrm{O}^{2-} .{ }^{15), 16)}$

The purpose of the present study is to investigate the diffusion of $\mathrm{O}_{2}$ in $\mathrm{SiO}_{2}$ utilizing its $\mathrm{PL}$ with taking the rate of the surface dissolution into account.

\section{Experimental procedure}

Synthetic $\mathrm{SiO}_{2}$ glass containing $\sim 2 \times 10^{18} \mathrm{~cm}^{-3}$ of $\mathrm{SiOH}$ groups was used as samples. First, the samples were thermally annealed in vacuum at $800,900,1000$, or $1100^{\circ} \mathrm{C}$ to relax the sample structure at the annealing temperature. It was followed by a thermal anneal in air at the same temperature as that of the vacuum anneal to incorporate $\mathrm{O}_{2}$ from ambient atmosphere. Then the concentrations of $\mathrm{O}_{2}$ were measured at ambient temperature by detecting its PL band at $1272 \mathrm{~nm}$ using a Fourier-transfer Raman spectrometer (Model 960, Nicolet) with a spectral resolution of $8 \mathrm{~cm}^{-1}$. The PL band was excited at $765 \mathrm{~nm}$ with a home-made continuous-wave titanium sapphire laser offering good stabilities of output wavelength $(\sim \pm 0.3 \mathrm{~nm})$ and power $(\sim \pm 1 \% \mathrm{rms})$. Thereby the fluctuation of PL intensity was minimized. The concentrations of $\mathrm{O}_{2}$ were determined from the ratios of PL intensities between the samples and a reference $\mathrm{SiO}_{2}$ glass with a known $\mathrm{O}_{2}$ content following the procedure described in Ref. 14) in detail.

\section{Mathematics for data analysis}

In this section, formula used to analyze the observed data will be presented. ${ }^{17), 2)}$ Assuming that there is a gradient of concentration only along the $x$-axis, concentration of diffus- 
ing substance at time $t$ and position $x, C(x, t)$, may follow the one-dimensional Fick's second law,

$$
\frac{\partial C(x, t)}{\partial t}=D \frac{\partial^{2} C(x, t)}{\partial x^{2}} .
$$

The diffusion coefficient $D$ can be taken as a constant when the concentration of diffusing substance is much less than the number of solubility sites per unit volume. Diffusion in a plane sheet whose thickness is $L$ and surfaces are at $x= \pm L / 2$ can be described by boundary conditions of $C( \pm L / 2, t)=C$ and $C(|x|<L / 2,0)=0$, where $C$ denotes the saturated concentration, i.e., the concentration in equilibrium with the partial pressure of the diffusing substance in the gas phase, $C=$ $\lim _{t \rightarrow \infty} C(x, t)$. The former condition postulates that the surface is always saturated with the diffusing substance because of its rapid dissolution. The solution of Eq. (1) under these conditions is

$$
\begin{aligned}
\frac{C(x, t)}{C}= & +\frac{4}{\pi} \sum_{n=1}^{\infty} \frac{(-1)^{n}}{2 n-1} \exp \left\{-\frac{D(2 n-1)^{2} \pi^{2} t}{L^{2}}\right\} \\
& \times \cos \frac{(2 n-1) \pi x}{L} .
\end{aligned}
$$

Integration of Eq. (2) between $x= \pm L / 2$ yields the average concentration at $t$,

$$
\frac{C_{\mathrm{a}}(t)}{C}=1-\frac{8}{\pi^{2}} \sum_{n=1}^{\infty} \frac{\exp \left\{-D(2 n-1)^{2} \pi^{2} t / L^{2}\right\}}{(2 n-1)^{2}} .
$$

However, the surface dissolution may be measurably slow if it involves significant activation processes. There are at least two different models to formulate such situation. ${ }^{17), 2)}$ The first model assumes that the flux across the surface is proportional to $C-C( \pm L / 2, t)$, the difference between the surface concentrations at $t \rightarrow \infty$ and $t$. Thus $C( \pm L / 2, t)$ is no longer a constant but satisfies the differential equation

$$
-\left.D \frac{\partial C(x, t)}{\partial x}\right|_{x= \pm L / 2}=\alpha\{C-C( \pm L / 2, t)\},
$$

where $\alpha$ is a coefficient representing the dissolution rate. Here, the solution of Eq. (1) becomes

$$
\frac{C(x, t)}{C}=1-\sum_{n=1}^{\infty} \frac{2 K \cos \left(2 \beta_{n} x / L\right) \exp \left(-4 \beta_{n}{ }^{2} D t / L^{2}\right)}{\left(\beta_{n}{ }^{2}+K^{2}+K\right) \cos \beta_{n}},
$$

where $K \equiv L \alpha / 2 D$ and $\beta_{n}$ denote the positive roots of $\beta \tan \beta=K$ satisfying $(n-1) \pi<\beta_{n}<(n-1 / 2) \pi$. The average concentration at $t$ is expressed by

$$
\frac{C_{\mathrm{a}}(t)}{C}=1-\sum_{n=1}^{\infty} \frac{2 K^{2} \exp \left(-4 \beta_{n}^{2} D t / L^{2}\right)}{\beta_{n}^{2}\left(\beta_{n}^{2}+K^{2}+K\right)} .
$$

In the second model, $C( \pm L / 2, t)$ is given as a root of a equation on exchange of diffusing substance between the surface and gas phase as

$$
-\frac{\partial C( \pm L / 2, t)}{\partial t}=k_{1} C_{\mathrm{g}}-k_{2} C( \pm L / 2, t),
$$

where $C_{\mathrm{g}}$ is the concentration of diffusing substance in the gas phase and $k_{1}$ and $k_{2}$ are the rate constants. Integration of Eq. (7) yields

$$
C( \pm L / 2, t)=C\{1-\exp (-\beta t)\},
$$

where relationships $C=k_{1} C_{\mathrm{g}} / k_{2}$ and $\beta=k_{2}$ hold. The solution of Eq. (1) under Eq. (8) is given by

$$
\begin{aligned}
\frac{C(x, t)}{C}= & 1-\exp (-\beta t) \frac{\cos \left(2 x K^{1 / 2} / L\right)}{\cos K^{1 / 2}} \\
& +\frac{4}{\pi} \sum_{n=1}^{\infty} \frac{(-1)^{n}}{2 n-1} \frac{\exp \left\{D(2 n-1)^{2} \pi^{2} t / L^{2}\right\}}{1-(2 n-1)^{2} \pi^{2} /(4 K)} \\
& \times \cos \frac{(2 n-1) \pi x}{L},
\end{aligned}
$$

where $K \equiv L^{2} \beta / 4 D$, and the average concentration is

$$
\begin{aligned}
\frac{C_{\mathrm{a}}(t)}{C}= & 1-\exp (-\beta t) K^{-1 / 2} \tan K^{1 / 2}-\frac{8}{\pi^{2}} \sum_{n=1}^{\infty} \frac{1}{(2 n-1)^{2}} \\
& \times \frac{\exp \left\{-D(2 n-1)^{2} \pi^{2} t / L^{2}\right\}}{1-(2 n-1)^{2} \pi^{2} /(4 K)} .
\end{aligned}
$$

In both models, the dimensionless parameter $K$ represents the normalized rate of the surface dissolution. At $K<100$, the delay of the surface dissolution becomes appreciable.

\section{Results}

To demonstrate the effects of rate of the surface dissolution, cross-sectional concentration profiles were simulated. Figures 1(a), (b), and (c) show $C(x, t)$ curves calculated from Eqs. (2), (5) and (9), respectively. The time-dependent saturation behaviors of the surface concentration are clearly different between profiles for slow surface dissolutions (Figs. 1(b) and (c)) and those of rapid dissolution (Fig. 1 (a) ). Thus the cross-sectional profile is useful to evaluate the rate of the surface dissolution.

The cross-sectional profiles were measured as follows. Samples with an initial dimension of $20 \times 20 \times 5 \mathrm{~mm}^{3}$ were loaded with $\mathrm{O}_{2}$. The concentration profile at the center of the sample was measured using a $20 \times 5 \times 2 \mathrm{~mm}^{3}$ parallelepiped quarried from the middle of the sample. The spatial resolution, determined by the positioning accuracy and the diameter of the
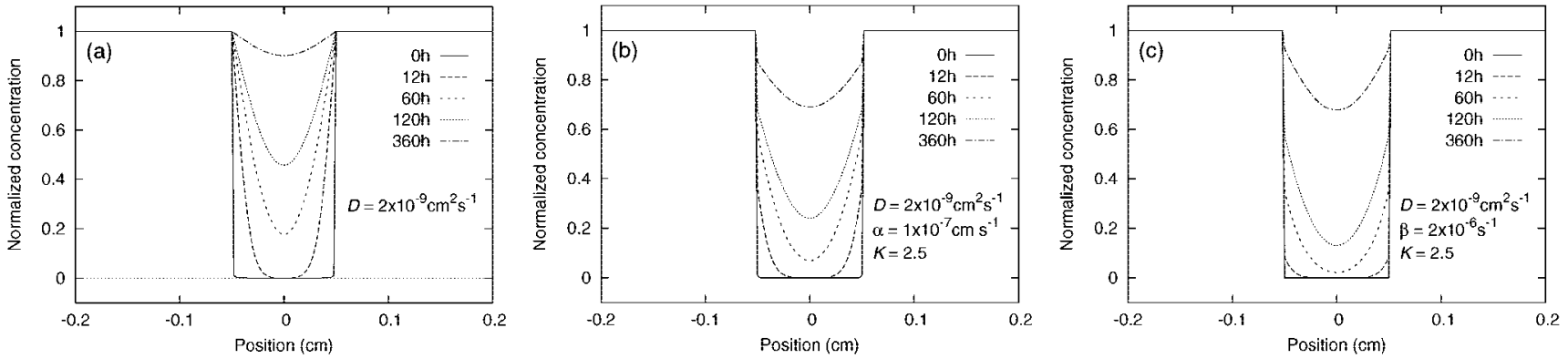

Fig. 1. Simulated cross-sectional concentration profiles calculated from (a) Eq. (2), (b) Eq. (5), and (c) Eq. (9). Parameters used for the calculations are shown in the figures. 


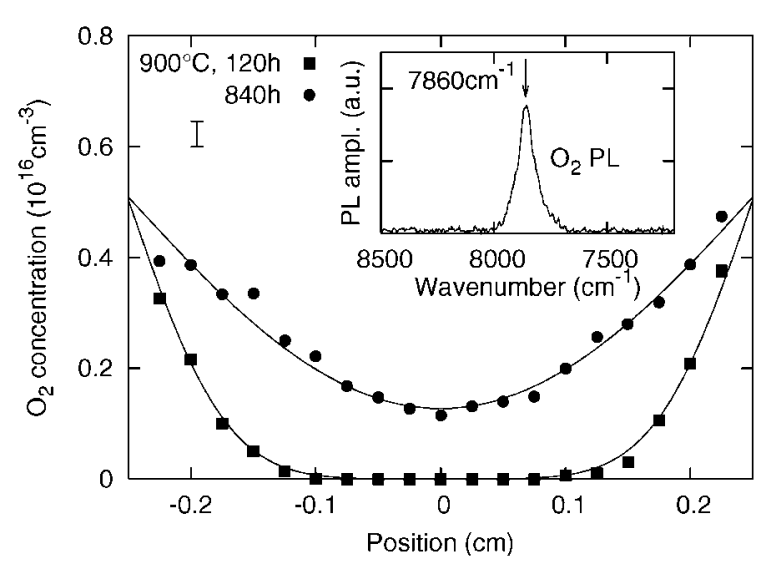

Fig. 2. Experimental and simulated cross-sectional concentration profiles of the interstitial $\mathrm{O}_{2}$ in $\mathrm{SiO}_{2}$ glass. The solid curves are drawn by fitting the experimental data points with Eq. (2). The inset shows the PL spectrum taken at $-0.20 \mathrm{~cm}$ for the sample thermally annealed for $840 \mathrm{~h}$.

focused excitation laser beam, was $\sim \pm 0.1 \mathrm{~mm}$. Figure 2 shows the results after thermal annealings for 120 and $840 \mathrm{~h}$ at $900^{\circ} \mathrm{C}$ and a typical PL spectrum. The data points were fitted with Eqs. (2), (5), or (9) using common fitting parameters for both curves. The obtained parameters were $D=4.4 \times 10^{-9}$ $\mathrm{cm}^{2} \cdot \mathrm{s}^{-1}$ and $C=5.1 \times 10^{15} \mathrm{~cm}^{-3}$ for Eq. (2); $D=4.4 \times 10^{-9}$ $\mathrm{cm}^{2} \cdot \mathrm{s}^{-1}, C=5.1 \times 10^{15} \mathrm{~cm}^{-3}$, and $\alpha=4.1 \times 10^{-6} \mathrm{~cm} \cdot \mathrm{s}^{-1}$ for Eq. (5); and $D=4.5 \times 10^{-9} \mathrm{~cm}^{2} \cdot \mathrm{s}^{-1}, C=5.1 \times 10^{15} \mathrm{~cm}^{-3}$, and $\beta=3.1 \times 10^{-5} \mathrm{~s}^{-1}$ for Eq. (9). Notably, these fittings yielded nearly the same $D$ and $C$ values and the simulated curves are almost identical with each other. Thus Fig. 2 only shows the curves calculated by Eq. (2). Further, the $K$ values were calculated to be $\sim 230$ for Eq. (5) and $\sim 430$ for Eq. (9), indicating that the dissolution of $\mathrm{O}_{2}$ at both surfaces is much faster than the diffusion of $\mathrm{O}_{2}$ in $\mathrm{SiO}_{2}$ glass. These analyses indicate that Eqs. (2) and (3) are accurate enough to describe the diffusion of the interstitial $\mathrm{O}_{2}$ in $\mathrm{SiO}_{2}$ glass.

An alternative way to evaluate the $D$ and $C$ values is to measure the average concentration $C_{\mathrm{a}}(t)$. This method is more convenient because it does not need the sample cutting after the $\mathrm{O}_{2}$ loading. The size of the samples was $10 \times 6.5 \times$ $1 \mathrm{~mm}^{3}$ and the PL spectra were measured at the center of the $10 \times 6.5 \mathrm{~mm}^{2}$ face. Figure 3 shows the $C_{\mathrm{a}}(t)$ data taken at $900^{\circ} \mathrm{C}$. Fitting of the result with Eq. (3) yielded $C=5.8 \times 10^{15}$ $\mathrm{cm}^{-3}$ and $D=4.7 \times 10^{-9} \mathrm{~cm}^{2} \cdot \mathrm{s}^{-1}$, showing a good agreement with the $D$ and $C$ values derived from Fig. 2 . These values at other temperatures were evaluated in a similar way. However, they can also be derived by analyzing the curve separately before and after the characteristic time defined as $t_{\mathrm{c}} \equiv \pi(L / 4)^{2} /$ $D$ : the height of the plateau at $t \gg t_{\mathrm{c}}$ equals $C$ as $C=C_{\mathrm{a}}(t \rightarrow \infty)$ while the slope of the $C_{\mathrm{a}}(t)-t^{1 / 2}$ curve at $t \ll t_{\mathrm{c}}$, is proportional to $D^{1 / 2}$ as $4 C(D / \pi)^{1 / 2} / L$.

All the $D$ and $C$ values determined in this study are summarized in Fig. 4. The dissolution of $\mathrm{O}_{2}$ in $\mathrm{SiO}_{2}$ glass follows the Henry's law, $C=S p\left(\mathrm{O}_{2}\right)$ when the partial pressure of $\mathrm{O}_{2}$ in the gas phase, $p\left(\mathrm{O}_{2}\right)$, is below several atm. ${ }^{3)}$ Thus we will define the solubility $S$ as $C$ under $p\left(\mathrm{O}_{2}\right)=1$ atm and use it here instead of $C$. Least-squares fittings of all $D$ values and $S$ values at $\leq 1000^{\circ} \mathrm{C}$ yielded

$$
D=3.6 \times 10^{-5 \pm 0.4} \mathrm{~cm}^{2} \cdot \mathrm{s}^{-1} \exp \left(\frac{-0.91 \pm 0.1 \mathrm{eV}}{k T}\right)
$$

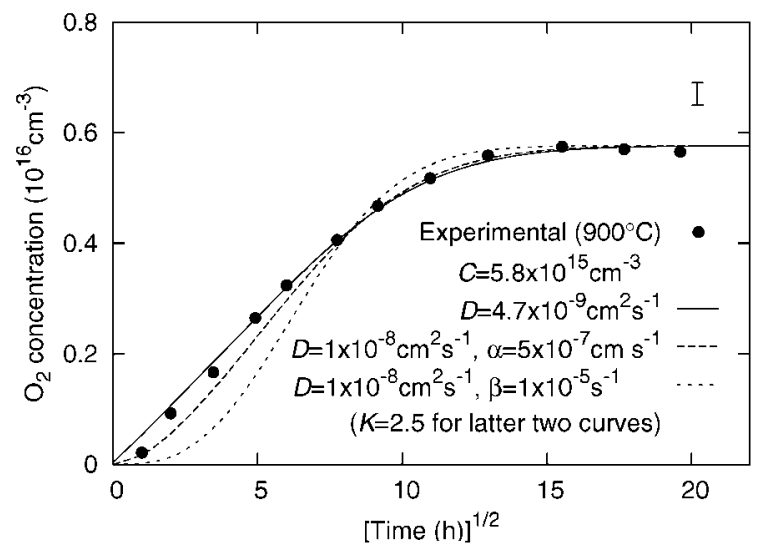

Fig. 3. Experimental and simulated changes of average concentration of the interstitial $\mathrm{O}_{2}$ in $\mathrm{SiO}_{2}$ glass. The experimental data points are fitted with Eq. (3) to evaluate $D$ and $C$ values. The other curves indicating the effect of slow surface dissolution are drawn by Eqs. (6) and (10) using parameters shown in the figure.
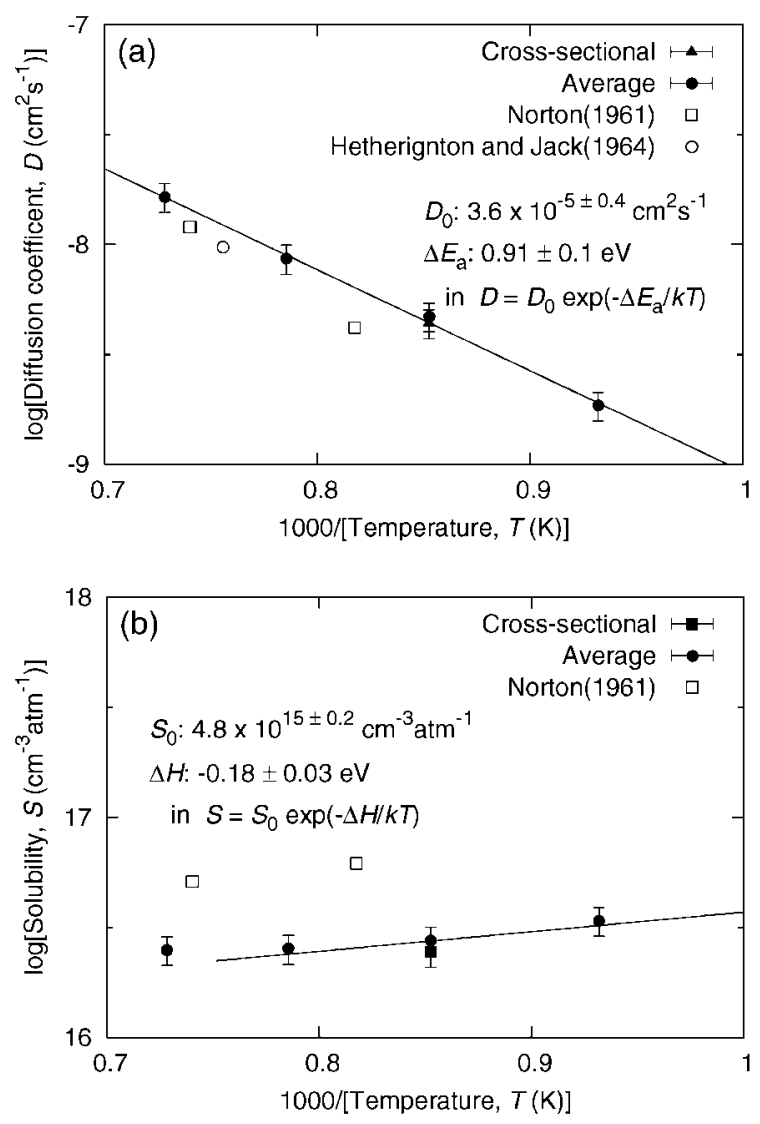

Fig. 4. Arrhenius plot of the (a) $D$ and (b) $S$ values obtained in this study. Data taken from Refs. 3) and 19) are shown too.

and,

$$
S=4.8 \times 10^{15 \pm 0.2} \mathrm{~cm}^{-3} \mathrm{~atm}^{-1} \exp \left(\frac{0.18 \pm 0.03 \mathrm{eV}}{k T}\right),
$$

respectively.

The effect of slow surface dissolution was examined by 


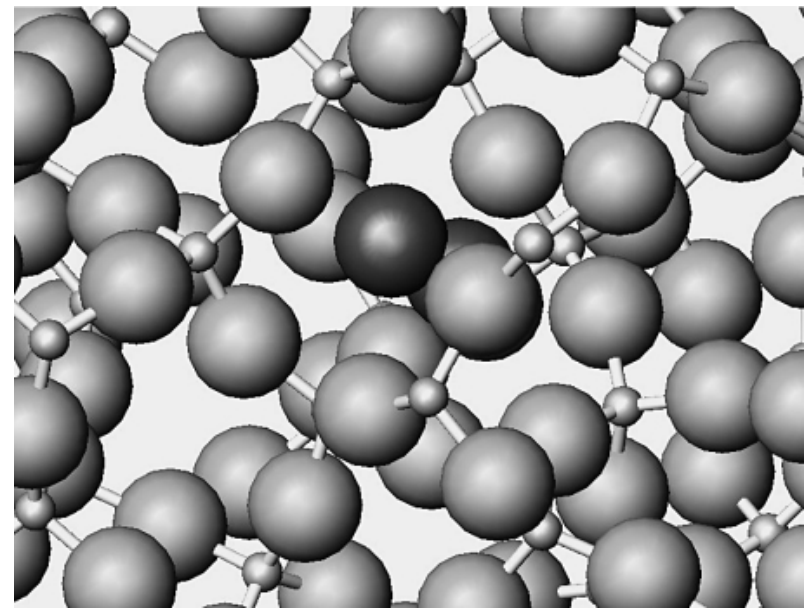

Fig. 5. Schematic illustration of the interstitial $\mathrm{O}_{2}$ (dark spheres) in $\mathrm{SiO}_{2}$ glass. Silicon and oxygen atoms are shown as small and large spheres, respectively.

simulating $C_{\mathrm{a}}(t)$ curves at $K=2.5$ from Eqs. (6) and (10) as shown in Fig. 2. These curves did not fit the experimental data well because of their slow initial growth and fast saturation, supporting the conclusion shown in Fig. 2. However, the shape of the $C_{\mathrm{a}}(t)$ curves varies less distinctly with $K$ than that of the $C(x, t)$ curves shown in Fig. 1 . Thus $K$ values were not evaluated here.

\section{Discussion}

The diffusion of oxygen in $\mathrm{SiO}_{2}$ glass measured so far can be classified into fast and slow ones. ${ }^{18)}$ The $D$ values reported in Refs. 3) and 19) are more than 5 orders of magnitude larger than those reported in other papers. ${ }^{4)-12)}$ The slow diffusion has been attributed to the movement of oxygen involving the hopping of oxygen atoms belonging to the $\mathrm{SiO}_{2}$ lattice. It is similar to the common mechanism of oxygen diffusion in oxides: diffusion via vacancy and interstitial sites. ${ }^{1)}$ On the other hand, compared to other oxides, structure of $\mathrm{SiO}_{2}$ glass is relatively sparse, allowing the incorporation of $\mathrm{O}_{2}$ as schematically shown in Fig. 5. Thus the fast diffusion has been suggested to be due to the transport of $\mathrm{O}_{2}$ without a significant interaction with the $\mathrm{SiO}_{2}$ lattice. $\left.{ }^{2)}{ }^{218}\right)$ This mechanism is supported by the following observations. In a permeation experiment in which the amount of gaseous species through thin $\mathrm{SiO}_{2}$ glass plates was measured, the permeation rate of species with a molecular mass 32 has found to be proportional to the partial pressure of $\mathrm{O}_{2}$ applied to the other surface. ${ }^{3)}$ This is an indication that the Henry's law holds for the dissolution of $\mathrm{O}_{2}$, further suggesting that $\mathrm{O}_{2}$ does not dissociate at the surfaces. The $D$ and $S$ values determined in Ref. 3) have been the standard parameters to predict the growth of insulating amorphous $\mathrm{SiO}_{2}$ films by thermal oxidation of silicon. ${ }^{20)}$ However, direct detection of the mobile species dominating the fast oxygen diffusion has not been reported.

In this study, diffusion of oxygen was measured by monitoring the concentration change of $\mathrm{O}_{2}$ in $\mathrm{SiO}_{2}$ glass. Analyses shown in Figs. 2 and 3 indicate that the incorpora- tion of $\mathrm{O}_{2}$ at the surface of $\mathrm{SiO}_{2}$ glass is much faster than its diffusion in $\mathrm{SiO}_{2}$ glass. Further, the observed $D$ and $S$ values agree well with those reported by Refs. 3) and 19). Thus we clearly demonstrate that the dissolution of $\mathrm{O}_{2}$ into $\mathrm{SiO}_{2}$ glass does not involve significant activation processes, and the subsequent diffusion of $\mathrm{O}_{2}$ through the interstitial spaces in $\mathrm{SiO}_{2}$ glass is responsible for the fast oxygen transport in $\mathrm{SiO}_{2}$ glass contributing to the thermal oxidation of silicon.

\section{Conclusions}

Surface dissolution and diffusion of $\mathrm{O}_{2}$ in $\mathrm{SiO}_{2}$ glass were studied by monitoring spatially resolved laser-induced photoluminescence of $\mathrm{O}_{2}$. The time- and positional-dependences of $\mathrm{O}_{2}$ concentration were theoretically analyzed by considering both the rates of dissolution at the surfaces and diffusion in the medium. This procedure verified that the interstitial $\mathrm{O}_{2}$ dominates long-range oxygen transport in $\mathrm{SiO}_{2}$ glass and its incorporation at the glass surfaces is not the rate-limiting process.

\section{References}

1) Kingery, W. D., Bowen, H. K. and Uhlmann, D. R., "Introduction to Ceramics," 2nd ed., John Wiley \& Sons, New York (1976).

2) Doremus, R. H., "Diffusion of Reactive Molecules in Solids and Melts," John Wiley \& Sons, New York (2002).

3) Norton, F. J., Nature, Vol. 191, pp. 701-701 (1961).

4) Haul, R. and Dümbgen, G., Z. Elektrochem., Vol. 66, pp. 636-641 (1962).

5) Sucov, E. W., J. Am. Ceram. Soc., Vol. 46, pp. 14-20 (1963).

6) Williams, E. L., J. Am. Ceram. Soc., Vol. 48, pp. 190-194 (1965).

7) Rosencher, R., Straboni, A., Rigo, S. and Amsel, G., Appl. Phys. Lett., Vol. 34, pp. 254-256 (1979).

8) Pfeffer, R. and Ohring, M., J. Appl. Phys., Vol. 52, pp. 777-784 (1981).

9) Mikkelsen, J. C., Jr., Appl. Phys. Lett., Vol. 45, pp. 1187-1189 (1984).

10) Costello, J. A. and Tressler, R. E., J. Electrochem. Soc., Vol. 131, pp. 1944-1947 (1984).

11) Han, C. J. and Helms, C. J., J. Appl. Phys., Vol. 59, pp. 1767-1769 (1986).

12) Kalen, J. D., Boyce, R. S. and Cawley, J. D., J. Am. Ceram. Soc., Vol. 74, pp. 203-209 (1991).

13) Skuja, L., Güttler, B., Schiel, D. and Silin, A. R., Phys. Rev. B, Vol. 58, pp. 14296-14304 (1998).

14) Kajihara, K., Miura, T., Kamioka, H., Hirano, M., Skuja, L. and Hosono, H., J. Non-Cryst. Solids, in press.

15) Manning, P. S., Sirman, J. D. and Kilner, J. A., Solid State Ionics, Vol. 93, pp. 125-132 (1997).

16) Ishihara, T., Kilner, J. A., Honda, M., Sakai, N., Yokokawa, H. and Takita, Y., Solid State Ionics, Vol. 113-115, pp. 593-600 (1998).

17) Crank, J., "The Mathematics of Diffusion," 2nd ed., Oxford University Press, Oxford (1975).

18) Lamkin, M. A., Riley, F. L. and Fordham, R. J., J. Eur. Ceram. Soc., Vol. 10, pp. 347-367 (1992).

19) Hetherington, G. and Jack, K. H., Phys. Chem. Glasses, Vol. 5, pp. 147-149 (1964).

20) Deal, B. E. and Grove, A. S., J. Appl. Phys., Vol. 36, pp. 3770-3778 (1965). 